\title{
The Effect of Time and Temperature Variables on Some Routine Coagulation Tests among Subjects of African Descent in Sokoto, North Western Nigeria
}

\author{
D. Ikhuenbor ${ }^{1}$, F. Aghedo', I. Z. Isah², I. Iwueke², R. A. Oladigbolu' ${ }^{3}$, N. B. Egenti , O. Erhabor ${ }^{2 *}$ \\ ${ }^{1}$ Department of Haematology and Blood Transfusion Science, Usmanu Danfodiyo University Teaching Hospital, Sokoto, Nigeria \\ ${ }^{2}$ Department of Haematology and Blood Transfusion Science, Faculty of Medical Laboratory Science, Usmanu Danfodiyo University, \\ Sokoto, Nigeria \\ ${ }^{3}$ Department of Community Medicine, Usmanu Danfodiyo University Teaching Hospital, Sokoto, Nigeria \\ ${ }^{4}$ Department of Community Medicine, Usmanu Danfodiyo University, Abuja, Nigeria \\ Email: ${ }^{\star}$ _osaro@yahoo.com
}

How to cite this paper: Ikhuenbor, D., Aghedo, F., Isah, I.Z., Iwueke, I., Oladigbolu, R.A., Egenti, N.B. and Erhabor, O. (2016) The Effect of Time and Temperature Variables on Some Routine Coagulation Tests among Subjects of African Descent in Sokoto, North Western Nigeria. Open Journa of Blood Diseases, 6, 79-88.

http://dx.doi.org/10.4236/ojbd.2016.64011

Received: October 20, 2016

Accepted: December 23, 2016

Published: December 26, 2016

Copyright $\odot 2016$ by authors and Scientific Research Publishing Inc. This work is licensed under the Creative Commons Attribution International License (CC BY 4.0).

http://creativecommons.org/licenses/by/4.0/

\section{Abstract}

This study evaluated the effects of time and temperature variables on routine Prothrombin Time test and Activated Partial Thromboplastin Time (APTT) test among subjects of African descent in Sokoto, North Western Nigeria. Samples of 99 subjects made up of 49 male and 50 female subjects with mean age $38.3 \pm 22.3$ years. Coagulation tests were performed immediately specified times after phlebotomy up to 24 hours $(0,1,2,3,4$ and 24 hours at room temperature of 40 degrees C. Our data demonstrate that prothrombin time and APTT results are stable for up to 2 hours, remaining constant regardless of storage conditions. Post hoc tests using Bonferroni correction revealed that there were increases in PT time from 0 hour to 4 hours (17.82 \pm 0.61 seconds vs $18.30 \pm 0.59$ seconds, respectively), from 0 hour to 24 hours (17.82 \pm 0.61 seconds vs $18.48 \pm 0.59$ seconds, respectively), from 2 hours to 4 hours (17.89 \pm 0.58 seconds vs $18.30 \pm 0.59$ seconds), from 2 hours to 24 hours $(17.89 \pm 0.58$ seconds vs $18.48 \pm 0.58$ seconds), which were all statistically significant $(\mathrm{p}=0.002$ and $\mathrm{p}<0.000, \mathrm{p}<0.000, \mathrm{p}<0.000$, respectively). However, the increase in PT time from 0 hour to 2 hours ( $17.82 \pm 0.61$ seconds vs $17.89 \pm 0.59$ seconds, respectively) and from 4 hours to 24 hours ( $18.30 \pm 0.59$ vs $18.48 \pm 0.59$ seconds, respectively) were not statistically significant $(\mathrm{p}=1, \mathrm{p}=0.428)$. A repeated measure ANOVA determined that mean PTTK time differed statistically significantly between time points $\mathrm{F}(3,291)=119.22, \mathrm{p}<0.001$. Post hoc tests using Bonferroni correction revealed that there were increase in PTTK time from 0 hour to 2 hours $(37.86 \pm 1.04$ seconds vs $39.94 \pm 1.07$ seconds, respectively), from 0 hour to 4 hours $(37.86 \pm 1.04$ seconds 
vs $42.34 \pm 1.11$ seconds, respectively), from 0 hours to 24 hours ( $37.86 \pm 1.04$ seconds vs $44.93 \pm 1.20$ seconds), from 2 hours to 4 hours (39.94 \pm 1.07 seconds vs $42.34 \pm$ 1.11 seconds), from 2 hours to 24 hours ( $39.94 \pm 1.07$ seconds vs $44.93 \pm 1.20 \mathrm{sec}$ onds) and from 4 hours to 24 hours $(42.43 \pm 1.11$ vs $44.93 \pm 1.20$ seconds), which were all statistically significant at $\mathrm{p}<0.001)$. Therefore, we conclude that there are no statistically significant differences in the PT and APTT between 0 and 2 hours. A longer timing (after 2 hours) from phlebotomy collection of blood from respondents elicited a statistically significant increase in the PT and APTT result. There were no statistically significant differences in the PT and APTT result determined 4 hours and 24 hours after phlebotomy. Longer timing from collection of blood from respondents elicited a statistically significant increment/increase in the clotting time using PTTK. Our data demonstrate that PT and APTT results are stable for 2 hours remaining constant regardless of storage conditions.

\section{Keywords}

Effect, Time, Temperature, Coagulation, African, Sokoto, Nigeria

\section{Introduction}

Pre-analytical and analytical variables including storage temperature and time interval between sample collection and testing can have a significant effect of results of hemostatic laboratory testing [1]. Pre-analytical variables including specimen collection, storage, temperature, transport, anticoagulant type, haematocrit, filling status of the sampling tube and centrifugation variable can potentially affect analysis results and by extension the medical care offered to patients [2]. Prothrombin time (PT), international normalized ratio (INR) and the Activated partial thromboplastin time (APTT are common and readily available coagulation tests used to investigate the pathological changes to the haemostatic and coagulation systems and to monitor clinical therapy particularly among patient on anticoagulant therapy (warfarin and Heparin), patients with thromboembolic events, haemorrhage and to monitor coagulopathy [2]. Prothrombin Time (PT) measures the integrity of the extrinsic system as well as factors common to both systems and Partial Thromboplastin Time (PTT) measures the integrity of the intrinsic system. The results of PT and APTT are used to diagnose haemophilia, are often associated with chronic liver disease, risk factors for thrombosis and are used as indicators for use of fresh-frozen plasma (FFP) in hemorrhaging patients and patients having an invasive procedure [3] [4]. To minimize the negative effects of pre-analytical variables, the Clinical and Laboratory Standards Institute (CLSI) H21-A5 recommends that specimens should be tested within $24 \mathrm{~h}$ for PT and $4 \mathrm{~h}$ for APTT if stored at room temperature $\left(25^{\circ} \mathrm{C}\right)$ [5]. Previous reports have suggested acceptable storage temperatures and times for routine coagulation testing [6] [7]. Storage time and temperature has been shown in a previous report to have effect on FVIII and FIX activity in FFP [4]. Normal temperature in our environment is $40^{\circ} \mathrm{C}$. It is not known what effect our local prevail- 
ing temperature has on PT and APTT results. The aim of this present study is of investigating the effect of storage temperature and time of testing on PT and APTT results. It is not known whether changes caused by delayed analyses and temperature have a clinically significant difference in the results obtained.

\section{Materials and Methods}

\subsection{Study Area}

The study was carried out in Usmanu Danfodiyo University Teaching Hospital (UDUTH), Sokoto, Nigeria. Sokoto State is located in the extreme North Western corner of Nigeria, it occupies 25,973 square kilometres and is situated along latitude $13^{\circ} 3^{\prime} 39^{\prime \prime} \mathrm{N}$ and longitude $5^{\circ} 14^{\prime} 2$ 'E. As of 2005, it had an estimated population of more than 4.2 million [8]. It shares its borders with Niger Republic to the North, Zamfara State to the East, Kebbi State to the South-East and Benin Republic to the West. With an annual average temperature of $28.3^{\circ} \mathrm{C}\left(82.9^{\circ} \mathrm{F}\right)$. Sokoto is in the dry Sahel, surrounded by Sandy Savannah and isolated Hills. Sokoto is on the whole, a very hot area.

\subsection{Study Subjects and Design}

The study included consecutively recruited patients referred for PT and APTT test in the Department of Haematology of Usmanu Danfodiyo University Teaching Hospital (UDUTH), Sokoto. Verbal informed consent was obtained from the subjects.

\subsection{Statistical Analysis}

Statistical analysis was performed using statistical package for social sciences (SPSS) version 20. Frequencies and percentages were calculated. Student $t$-test (independent $t$ test and paired sample t-test) and ANOVA were used for comparison of data. The results were presented as mean \pm standard error of mean. A p-value of $\leq 0.05$ was considered as significant in all statistical comparisons.

\subsection{Inclusion Criteria}

Inclusion criteria included Clinical Indication and request for PT and APTT by a clinician and willingness of subject to offer verbal informed consent to participate as subject in this study.

\subsection{Exclusion Criteria}

The following were excluded from the study; patients in whom PT and APTT were not clinically indicated and patients who refused to offer a verbal informed consent to participate as subject in this study.

\subsection{Study Design}

This research was a case study and included 99 subjects made up of 49 male and 50 female subjects with mean age $38.3 \pm 22.3$ years. Socio-demographic data of the patients was obtained by using a questionnaire which included the age, gender and other socio- 
demographic data.

\subsection{Study Site and Participating Hospital}

Study was conducted in the Haematology Laboratory of the Faculty of Medical Laboratory Sciences, Usmanu Danfodiyo University, Sokoto, Nigeria.

\subsection{Sample Collection}

About 2.7 millilitres of blood sample was collected from each subject aseptically using the venepuncture technique. The blood was collected into tubes containing sodium citrate anticoagulant. The citrated samples were centrifuged at $3000 \mathrm{rpm}$ for 5 minutes to obtain clear non-haemolysed citrated plasma. The plasma was transferred into sterile labelled test tubes and assayed (in batches) for PT and APTT using the Diagen (UK) PT and APTT kits.

\section{Result}

This study evaluated the effects of time and temperature variables on routine Prothrombin Time test and Activated Partial Thromboplastin Time (APTT) test among subjects of African descent in Sokoto, North Western Nigeria. Samples 99 subjects made up of $49(49.5 \%)$ male and $50(50.5 \%)$ female subjects with mean age $38.3 \pm 22.3$ years. Table 1 show the age and gender distribution of subjects. Coagulation tests were performed immediately specified times after phlebotomy up to 24 hours $(0,1,2,3,4$ and 24 hours at room temperature of 40 degrees $\mathrm{C}$. Our data demonstrate that prothrombin time and APTT results are stable for up to 2 hours, remaining constant regardless of storage conditions. Table 2 and Table 3 show the mean PT and APTT results respectively

Table 1. Age and gender distribution of subjects.

\begin{tabular}{cc}
\hline Age group (Years) & Frequency (\%) \\
\hline Age & $5(6.2)$ \\
$0-9$ & $12(14.8)$ \\
$10-19$ & $16(19.8)$ \\
$20-29$ & $14(17.3)$ \\
$30-39$ & $10(12.3)$ \\
$40-49$ & $8(9.9)$ \\
$50-59$ & $6(7.4)$ \\
$60-69$ & $6(7.4)$ \\
$70-79$ & $3(3.7)$ \\
$80-89$ & 0 \\
$90-99$ & $1(1.2)$ \\
$100-109$ & Mean $=38.3 \pm 22.3$ years \\
Gender & \\
Male & \\
Female & $49(49.5)$ \\
\hline
\end{tabular}


Table 2. Mean PT results of subjects done hourly over a 4 hours period.

\begin{tabular}{ccccc}
\hline \multirow{2}{*}{ Time (Hours) } & \multicolumn{4}{c}{ PT (95\% Confidence Interval) } \\
\cline { 2 - 5 } & Mean & Std. Error & Lower Bound & Upper Bound \\
\hline $\mathbf{1}$ & 17.818 & 0.605 & 16.617 & 19.020 \\
$\mathbf{2}$ & 17.889 & 0.579 & 16.739 & 19.039 \\
$\mathbf{3}$ & 18.303 & 0.596 & 17.121 & 19.486 \\
$\mathbf{4}$ & 18.475 & 0.589 & 17.306 & 19.644 \\
\hline
\end{tabular}

Table 3. Differences between the mean time for PTTK when done over time.

\begin{tabular}{ccccc}
\hline \multirow{2}{*}{ Time (Hours) } & \multicolumn{4}{c}{ PTTK (95\% Confidence Interval) } \\
\cline { 2 - 5 } & Mean & Std. Error & Lower Bound & Upper Bound \\
\hline $\mathbf{1}$ & 37.857 & 1.040 & 35.792 & 39.922 \\
$\mathbf{2}$ & 39.939 & 1.070 & 37.815 & 42.063 \\
$\mathbf{3}$ & 42.337 & 1.112 & 40.130 & 44.543 \\
$\mathbf{4}$ & 44.929 & 1.201 & 42.545 & 47.312 \\
\hline
\end{tabular}

of subjects done hourly over a 4 hours period. A repeated measure ANOVA with sphericity assumed determined that mean PT time differed statistically significantly between time points $\mathrm{F}(3,294)=16.294, \mathrm{p}<0.001$. Post hoc tests using Bonferroni correction revealed that there were increase in PT time from ohour to 4 hours (17.82 \pm 0.61 seconds vs $18.30 \pm 0.59$ seconds, respectively), from 0 hour to 24 hours (17.82 \pm 0.61 seconds vs $18.48 \pm 0.59$ seconds, respectively), from 2 hours to 4 hours (17.89 \pm 0.58 seconds vs $18.30 \pm 0.59$ seconds), from 2 hours to 24 hours ( $17.89 \pm 0.58$ seconds vs $18.48 \pm 0.58$ seconds), which were all statistically significant $(\mathrm{p}=0.002$ and $\mathrm{p}<0.000$, $\mathrm{p}<0.000, \mathrm{p}<0.000$, respectively). However, the increase in PT time from 0 hour to 2 hours (17.82 \pm 0.61 seconds vs $17.89 \pm 0.59$ seconds, respectively) and from 4 hours to 24 hours (18.30 \pm 0.59 vs $18.48 \pm 0.59$ seconds, respectively) were not statistically significant ( $\mathrm{p}=1, \mathrm{p}=0.428$ ). Table 3 shows the Bonferroni comparison between the Mean Time for PT when done over Time.

A repeated measure ANOVA determined that mean PTTK time differed statistically significantly between time points $\mathrm{F}(3,291)=119.22, \mathrm{p}<0.001$. Post hoc tests using Bonferroni correction revealed that there were increase in PTTK time from 0 hour to 2 hours (37.86 \pm 1.04 seconds vs $39.94 \pm 1.07$ seconds, respectively), from 0 hour to 4 hours ( $37.86 \pm 1.04$ seconds vs $42.34 \pm 1.11$ seconds, respectively), from 0 hours to 24 hours (37.86 \pm 1.04 seconds vs $44.93 \pm 1.20$ seconds), from 2 hours to 4 hours (39.94 \pm 1.07 seconds vs $42.34 \pm 1.11$ seconds), from 2 hours to 24 hours (39.94 \pm 1.07 seconds vs $44.93 \pm 1.20$ seconds) and from 4 hours to 24 hours ( $42.43 \pm 1.11$ vs $44.93 \pm 1.20$ seconds), which were all statistically significant at $\mathrm{p}<0.001)$. Table 4 shows the Bonferroni comparison between the mean time for APPT when done over time. Table 5 shows the differences between the Mean Time for PTTK when done over Time.

\section{Discussion}

In this present study, PT and APTT tests were performed immediately at specified 
Table 4. Differences between the mean time for PT when done over time.

\begin{tabular}{|c|c|c|c|c|c|c|}
\hline \multicolumn{7}{|c|}{ Pairwise Comparisons } \\
\hline \multicolumn{7}{|c|}{ Measure: PT } \\
\hline \multirow{2}{*}{ (I) Time (J) } & \multirow{2}{*}{ Time } & \multirow{2}{*}{ Mean Difference (I-J) } & \multirow{2}{*}{\multicolumn{2}{|c|}{ Std. Error p-value ${ }^{\mathrm{b}}$}} & \multicolumn{2}{|c|}{ 95\% Confidence Interval for Difference } \\
\hline & & & & & Lower Bound & Upper Bound \\
\hline \multirow{3}{*}{1} & 2 & -0.071 & 0.082 & 1.000 & -0.290 & 0.149 \\
\hline & 3 & $-0.485^{\star}$ & 0.128 & $0.002^{*}$ & -0.829 & -0.140 \\
\hline & 4 & $-0.657^{\star}$ & 0.144 & $0.000^{*}$ & -1.045 & -0.268 \\
\hline \multirow{3}{*}{2} & 1 & 0.071 & 0.082 & 1.000 & -0.149 & 0.290 \\
\hline & 3 & $-0.414^{*}$ & 0.094 & $0.000^{*}$ & -0.668 & -0.161 \\
\hline & 4 & $-0.586^{*}$ & 0.114 & $0.000^{\star}$ & -0.893 & -0.279 \\
\hline \multirow{3}{*}{3} & 1 & $0.485^{\star}$ & 0.128 & $0.002^{*}$ & 0.140 & 0.829 \\
\hline & 2 & $0.414^{*}$ & 0.094 & $0.000^{*}$ & 0.161 & 0.668 \\
\hline & 4 & -0.172 & 0.094 & 0.428 & -0.425 & 0.082 \\
\hline \multirow{3}{*}{4} & 1 & $0.657^{\star}$ & 0.144 & $0.000^{*}$ & 0.268 & 1.045 \\
\hline & 2 & $0.586^{*}$ & 0.114 & $0.000^{\star}$ & 0.279 & 0.893 \\
\hline & 3 & 0.172 & 0.094 & 0.428 & -0.082 & 0.425 \\
\hline
\end{tabular}

Based on estimated marginal means. ${ }^{\star}$ The mean difference is significant at the 0.05 level; ${ }^{\mathrm{b}}$ Adjustment for multiple comparisons: Bonferroni.

Table 5. Differences between the mean time for PTTK when done over time.

\begin{tabular}{|c|c|c|c|c|c|c|}
\hline \multicolumn{7}{|c|}{ Pairwise Comparisons } \\
\hline \multicolumn{7}{|c|}{ Measure: PTTK } \\
\hline \multirow{2}{*}{ (I) Time (J) } & \multirow{2}{*}{ Time } & \multirow{2}{*}{ Mean Difference (I-J) } & \multirow{2}{*}{ Std. Error } & \multirow{2}{*}{$\mathrm{Sig}^{\mathrm{b}}$} & \multicolumn{2}{|c|}{ 95\% Confidence Interval for Difference } \\
\hline & & & & & Lower Bound & Upper Bound \\
\hline \multirow{3}{*}{1} & 2 & $-2.082^{*}$ & 0.264 & 0.000 & -2.792 & -1.371 \\
\hline & 3 & $-4.480^{*}$ & 0.381 & 0.000 & -5.505 & -3.454 \\
\hline & 4 & $-7.071^{\star}$ & 0.551 & 0.000 & -8.556 & -5.587 \\
\hline \multirow{3}{*}{2} & 1 & $2.082^{\star}$ & 0.264 & 0.000 & 1.371 & 2.792 \\
\hline & 3 & $-2.398^{*}$ & 0.273 & 0.000 & -3.133 & -1.663 \\
\hline & 4 & $-4.990^{*}$ & 0.466 & 0.000 & -6.245 & -3.735 \\
\hline \multirow{3}{*}{3} & 1 & $4.480^{\star}$ & 0.381 & 0.000 & 3.454 & 5.505 \\
\hline & 2 & $2.398^{\star}$ & 0.273 & 0.000 & 1.663 & 3.133 \\
\hline & 4 & $-2.592^{\star}$ & 0.358 & 0.000 & -3.555 & -1.629 \\
\hline \multirow{3}{*}{4} & 1 & $7.071^{*}$ & 0.551 & 0.000 & 5.587 & 8.556 \\
\hline & 2 & $4.990^{*}$ & 0.466 & 0.000 & 3.735 & 6.245 \\
\hline & 3 & $2.592^{*}$ & 0.358 & 0.000 & 1.629 & 3.555 \\
\hline
\end{tabular}

Based on estimated marginal means. ${ }^{*}$ The mean difference is significant at the 0.05 level. ${ }^{b}$ Adjustment for multiple comparisons: Bonferroni.

times after phlebotomy up to 24 hours $(0,1,2,3,4$ and 24 hours at room temperature of 40 degrees $\mathrm{C}$ ). Our data demonstrate that there are no statistically significant differences in the PT and APTT between 0 and 2 hours. A longer timing (after 2 hours) from phlebotomy elicited a statistically significant increase in the PT and APTT result. Our 
finding is at variance with observation in a previous report [9] which indicated that $\mathrm{PT} / \mathrm{INR}$ result is clinically relevant after storage for up to $24 \mathrm{~h}$ at $4^{\circ} \mathrm{C}$ and $25^{\circ} \mathrm{C}$; while APTT could be stored for up to $12 \mathrm{~h}$ at $4^{\circ} \mathrm{C}$ and $8 \mathrm{~h}$ at $25^{\circ} \mathrm{C}$. Our finding is also at variance with a previous report which indicated that prothrombin time and APTT results are stable for up to $24 \mathrm{~h}$ and $8 \mathrm{~h}$ respectively, remaining constant regardless of storage conditions [10]. Also, Goyal and colleagues [11] evaluated coagulation parameters (PT and APTT) at 0, 6, 24 and $48 \mathrm{~h}$ from the plasma stored at room temperature, as well as plasma stored under refrigerated and freezing conditions and observed that PT can be stored and analysed without any significant changes for up to $6 \mathrm{~h}$ from the actual blood collection, while for APTT results, plasma samples should be run immediately after collection. Our finding is consistent with previous report [12] which indicated that APTT samples can be accepted up to $2 \mathrm{~h}$ only at RT or Refrigerator. Our acceptable time intervals for PT and APTT determination are shorter than those recommended in the CLSI H21-A5 guidelines [5] which recommend that specimens should be analyzed within $24 \mathrm{~h}$ for PT and $4 \mathrm{~h}$ for APTT and other assays if stored at room temperature $\left(25^{\circ} \mathrm{C}\right)$. Our finding is also at variance with previous reports [13] [14] [15] [16] [17] which reported that PT and APTT can be reliably tested after storage for $8 \mathrm{~h}$ at room temperature and that the acceptable time interval can easily be extended to $24 \mathrm{~h}$ for PT determination.

In variance to our findings, van Geest-Daalderop and colleagues [18] reported that the acceptable time interval for PT/INR determination is $6 \mathrm{~h}$ at $4^{\circ} \mathrm{C}-6^{\circ} \mathrm{C}, 25^{\circ} \mathrm{C}$, and $37^{\circ} \mathrm{C}$. Moreover, Oddoze and colleagues [15] reported that the acceptable time interval for APTT determination is $6 \mathrm{~h}$ at $4^{\circ} \mathrm{C}$ and $25^{\circ} \mathrm{C}$. Our finding is partly in agreement with a previous report by Mohammed Saghir and colleagues [12] who reported that samples for PT testing can be accepted only up to $4 \mathrm{~h}$ when kept at RT while samples for APTT can be accepted up to $2 \mathrm{~h}$ only at RT or refrigerator. Our finding is also slightly at variance with a previous report [19] which indicated that prothrombin time (PT) and activated partial thromboplastin time (APTT) should be completed within one hour of sample collection and the storage temperature should be at room temperature. The reason for our distinct finding compared to other authors is that unlike others, the prevailing room temperature under which our testing was carried out was at $40^{\circ} \mathrm{C}$.

We observed that there were no statistically significant differences in the PT and APTT result determined 4 hours and 24 hours after phlebotomy. Longer timing from collection of blood from respondents seems to elicit a statistically significant increment/increase in the clotting time using PT and PTTK. Our finding is also at variance with findings by previous authors [20] [21] who concluded that no changes were noted in PT and APTT up to $6 \mathrm{~h}$ and $8 \mathrm{~h}$ respectively. Similarly, a previous study carried out by Salvagno and colleagues [22] indicated that a 6-h storage of uncentrifuged specimens at either RT or 4 degrees $\mathrm{C}$ may still be suitable to achieve results of routine coagulation testing comprised within the analytical quality specifications for desirable bias.

In this study, we observed an increase in the PT and APTT measurements was noted over time when samples were stored at the prevailing temperature of $40^{\circ} \mathrm{C}$. Previous 
report indicated that $\mathrm{APTT}$ measurements were increased at $4^{\circ} \mathrm{C}$ while $\mathrm{PT}$ measurements were decreased at $4^{\circ} \mathrm{C}$ [23]. Similarly, Heil and colleagues [24] demonstrated that APTT samples were stable up to $8 \mathrm{~h}$ at either RT or $4^{\circ} \mathrm{C}$, except for those which were on unfractionated heparin therapy. Several studies recommended that PT and APTT determinations may be constant for periods more than currently suggested in NCCLS guidelines [25] [26]. PT, and APTT are part of the conventional routine coagulation panel. This study has shown that accurate standardization of both the preanalytical and analytical phases is pivotal to achieving accuracy and precision of results. There may be need for timely and accurate coagulation testing of plasma samples in environment where prevailing room temperature is higher than the CLSI H21-A5 guidelines prescribed threshold room temperature of $25^{\circ} \mathrm{C}$. Coagulation testing is very important to diagnose and treat haemophilia, in management of haemorrhage, to monitor oral anticoagulant therapy, chronic liver disease, in thrombotic disease and in the determination of patients in which FFP is clinically indicated.

\section{Conclusion and Recommendations}

This study has shown that there are no statistically significant differences in the PT and APTT between 0 and 2 hours. A longer timing (after 2 hours) from phlebotomy collection of blood from respondents elicited a statistically significant increase in the PT and APTT result. There may be need for timely and accurate coagulation testing of plasma samples in environment where prevailing room temperature is higher that the CLSI $\mathrm{H} 21-\mathrm{A} 5$ guidelines prescribed threshold room temperature of $25^{\circ} \mathrm{C}$.

\section{References}

[1] Lippi, G., Guidi, G.C., Mattiuzzi, C. and Plebani, M. (2006) Preanalytical Variability: The Dark Side of the Moon in Laboratory Testing. Clinical Chemistry and Laboratory Medicine, 44, 358-365. https://doi.org/10.1515/cclm.2006.073

[2] Zhao, Y. and Lv, G. (2013) Influence of Temperature and Storage Duration on Measurement of Activated Partial Thromboplastin Time, D-Dimers, Fibrinogen, Prothrombin Time and Thrombin Time, in Citrate-Anticoagulated Whole Blood Specimens. International Journal of Laboratory Hematology, 35, 566-570. https://doi.org/10.1111/ijlh.12113

[3] Prelipcean, C.C., Fierbinteanu-Braticevici, C., Drug, V.L., Lăcătuşu, C., Mihai, B. and Mihai. C. (2011) Liver Cirrhosis-Procoagulant Stasis. Revista Medico-Chirurgicala a Societatii De Medici Si Naturalisti Din Iasi, 115, 678-685.

[4] Omidkhoda, A., Tabatabaei, M.R., Atarodi, K., Karimi, K., Froushani, A.R. and Pourfathollah, A.A. (2011) A Comparative Study of the Effects of Temperature, Time and Factor VIII Assay Type on Factor VIII Activity in Cryoprecipitate in Iran. Blood Transfusion, 9, 394399.

[5] Clinical and Laboratory Standards Institute (2008) Approved Guideline: Fifth Edition (H21-A5). Clinical and Laboratory Standards Institute, 28, 1-33.

[6] Zürcher, M., Sulzer, I., Barizzi, G., Lammle, B. and Alberio, L. (2008) Stability of Coagulation Assays Performed in Plasma from Citrated Whole Blood Transported at Ambient Temperature. Thrombosis and Haemostasis, 99, 416-426.

https://doi.org/10.1160/th07-07-0448 
[7] van Geest-Daalderop, J.H., Mulder, A.B., Boonman-de Winter, L.J., Hoekstra, M.M. and van den Besselaar, A.M. (2005) Preanalytical Variables and Off-Site Blood Collection: Influences on the Results of the Prothrombin Time/International Normalized Ratio Test and Implications for Monitoring of Oral Anticoagulant Therapy. Clinical Chemistry, 51, 561568. https://doi.org/10.1373/clinchem.2004.043174

[8] National Population Commission (NPC) (2007) National Census Figures, Abuja, Nigeria. http://www.population.gov.ng/

[9] Feng, L., Zhao, Y., Zhao, H. and Shao, Z. (2014) Effects of Storage Time and Temperature on Coagulation Tests and Factors in Fresh Plasma. Science Report, 4, 3868. https://doi.org/10.1038/srep03868

[10] Adcock, D., Kressin, D. and Marlar, R.A. (1998) The Effect of Time and Temperature Variables on Routine Coagulation Tests. Blood Coagul Fibrinolysis, 9, 463-470. https://doi.org/10.1097/00001721-199809000-00002

[11] Goyal, V.K., Kakade, S., Pandey, S.K., Gothi, A.K. and Nirogi, R. (2015) Determining the Effect of Storage Conditions on Prothrombin Time, Activated Partial Thromboplastin Time and Fibrinogen Concentration in Rat Plasma Samples. Laboratory Animal, 49, 311-318. https://doi.org/10.1177/0023677215597137

[12] Mohammed Saghir, S.A., Al-Hassan, F.M., Alsalahi, O.S., Abdul Manaf, F.S. and Baqir, H.S. (2012) Optimization of the Storage Conditions for Coagulation Screening Tests. Journal of College of Physicians and Surgery of Pakistan, 22, 294-297.

[13] Wang, X., Ma, J. and Hao, Z.L. (2002) Influence of Storage Time of PT and APTT at Different Temperature. Journal of Hebei Medical University, 23, 108-109.

[14] Wang, B.L., Guo, W.L. and Pan, B.S.H. (2011) Influence of Storage Time at Room Temperature on Routine Coagulation Tests. Chinese Journal of Laboratory Medicine, 34, 595-597.

[15] Oddoze, C., Lombard, E. and Portugal, H. (2012) Stability Study of 81 Analytes in Human Whole Blood, in Serum and in Plasma. Clinical Biochemistry, 45, 464-469. https://doi.org/10.1016/j.clinbiochem.2012.01.012

[16] Rao, L.V., Okorodudu, A.O., Petersen, J.R. and Elghetany, M.T. (2000) Stability of Prothrombin Time and Activated Partial Thromboplastin Time Tests under Different Storage Conditions. Clinical Chemical Acta, 300, 13-21. https://doi.org/10.1016/S0009-8981(00)00288-6

[17] Kemkes-Matthes, B., Fischer. R. and Peetz, D. (2011) Influence of 8 and 24-h Storage of Whole Blood at Ambient Temperature on Prothrombin Time, Activated Partial Thromboplastin Time, Fibrinogen, Thrombin Time, Antithrombin and D-Dimer. Blood Coagulation and Fibrinolysis, 22, 215-220. https://doi.org/10.1097/MBC.0b013e328343f8bf

[18] Van Geest-Daalderop, J.H., Mulder, A.B., de Winter, L.J., Hoekstra, M.M. and van den Besselaar, A.M. (2005) Preanalytical Variables and Off-Site Blood Collection: Influences on the Results of the Prothrombin Time/International Normalized Ratio Test and Implications for Monitoring of Oral Anticoagulant Therapy. Clinical Chemical Acta, 51, 561-568. https://doi.org/10.1373/clinchem.2004.043174

[19] Komiyama, Y. (2015) Samples in Coagulation Test. Rinsho Byori, 63, 1397-1404.

[20] Koepke, J.A., Rodgers, J.L. and Ollivier, M.J. (1975) Pre-Instrumental Variables in Coagulation Testing. American Journal Clinical Pathology, 64, 591-596. https://doi.org/10.1093/ajcp/64.5.591

[21] Neofotistos, D., Oropeza, M. and Ts'ao, C.H. (1998) Stability of Plasma for Add on PT and APTT Tests. American Journal Clinical Pathology, 109, 758-763. https://doi.org/10.1093/ajcp/109.6.758 
[22] Salvagno, G.L., Lippi, G., Montagnana, M., Franchini, M., Poli, G. and Guidi, G.C. (2009) Influence of Temperature and Time before Centrifugation of Specimens for Routine Coagulation Testing. International Journal of Laboratory Hematolology, 31,462-467. https://doi.org/10.1111/j.1751-553X.2008.01058.x

[23] Tabata, H., Nakamura, S. and Matszawa, T. (1995) Some Species Differences in the False Prolongation of Prothrombin Times and Activated Partial Thromboblastin Times in Toxicology. Comparative Haematology International, 5, 140-144.

https://doi.org/10.1007/BF00638933

[24] Heil, W., Grunewald, R., Amend, M. and Heins, M. (1998) Influence of Time and Temperature on Coagulation Analyses in Stored Plasma. Clinical Chemistry Laboratory Medicine, 36, 459-462. https://doi.org/10.1515/CCLM.1998.077

[25] Fiore, L.D., Brophy, M.T. and Hankins, M. (1993) The Effect of Blood Sample Storage and Transport on the PT in Anticoagulated Patients. Thrombosis and Haemostasis, 69, 676-679.

[26] Clinical and Laboratory Standards Institute (2003) Collection, Transport, and Processing of Blood Specimens for Testing Plasma-Based Coagulation Assays. CLSI, Wayne.

Submit or recommend next manuscript to SCIRP and we will provide best service for you:

Accepting pre-submission inquiries through Email, Facebook, LinkedIn, Twitter, etc.

A wide selection of journals (inclusive of 9 subjects, more than 200 journals)

Providing 24-hour high-quality service

User-friendly online submission system

Fair and swift peer-review system

Efficient typesetting and proofreading procedure

Display of the result of downloads and visits, as well as the number of cited articles

Maximum dissemination of your research work

Submit your manuscript at: http://papersubmission.scirp.org/

Or contact ojbd@scirp.org 